\title{
Spatial and temporal variation in malaria transmission in a low endemicity area in northern Tanzania
} MJAM Oesterholt ${ }^{1,2}$, JT Bousema ${ }^{2}$, OK Mwerinde ${ }^{1,3}$, C Harris ${ }^{1}$, P Lushino ${ }^{1,3}$, A Masokoto ${ }^{1,3}, \mathrm{H} \mathrm{Mwerinde}^{4}$, FW Mosha ${ }^{3}$ and CJ Drakeley*1,5

Address: ${ }^{1}$ Joint Malaria Programme, Moshi, Tanzania, ${ }^{2}$ Department of Medical Microbiology, Radboud University Nijmegen Medical Centre, Nijmegen, The Netherlands, ${ }^{3}$ Kilimanjaro Christian Medical Centre, Moshi, Tanzania, ${ }^{4}$ TPC Hospital, Moshi, Tanzania and ${ }^{5}$ London School of Hygiene and Tropical Medicine, London, UK

Email: MJAM Oesterholt - maykeoesterholt@student.ru.nl; JT Bousema - t.bousema@ncmls.ru.nl; OK Mwerinde - okmwerinde@hotmail.com; C Harris - caroline.harris@lshtm.ac.uk; P Lushino - palushino@yahoo.co.uk; A Masokoto - amasokoto@hotmail.com;

H Mwerinde - hospital@tpc.co.tz; FW Mosha - fwmosha@hotmail.com; CJ Drakeley* - chris.drakeley@lshtm.ac.uk

* Corresponding author

Published: 03 November 2006

Malaria Journal 2006, 5:98 doi:10.1 /86/1475-2875-5-98

This article is available from: http://www.malariajournal.com/content/5/l/98

(C) 2006 Oesterholt et al; licensee BioMed Central Ltd.

This is an Open Access article distributed under the terms of the Creative Commons Attribution License (http://creativecommons.org/licenses/by/2.0), which permits unrestricted use, distribution, and reproduction in any medium, provided the original work is properly cited.
Received: 22 September 2006

Accepted: 03 November 2006

\begin{abstract}
Background: Spatial and longitudinal monitoring of transmission intensity will allow better targeting of malaria interventions. In this study, data on meteorological, demographic, entomological and parasitological data over the course of a year was collected to describe malaria epidemiology in a single village of low transmission intensity.
\end{abstract}

Methods: Entomological monitoring of malaria vectors was performed by weekly light trap catches in 10 houses. Each house in the village of Msitu wa Tembo, Lower Moshi, was mapped and censused. Malaria cases identified through passive case detection at the local health centre were mapped by residence using GIS software and the incidence of cases by season and distance to the main breeding site was calculated.

Results: The principle vector was Anopheles arabiensis and peak mosquito numbers followed peaks in recent rainfall. The entomological inoculation rate estimated was $3.4(95 \% \mathrm{Cl} 0.7-9.9)$ infectious bites per person per year. The majority of malaria cases $(85 / / 30)$ occurred during the rainy season $\left(\chi^{2}=62,3, p<0.001\right.$ ). Living further away from the river (OR 0.96, $\mathrm{Cl} 0.92-0.998, \mathrm{p}=0.04$ every $50 \mathrm{~m}$ ) and use of anti-insect window screens (OR 0.65, Cl 0.44-0.94, $\mathrm{p}=0.023$ ) were independent protective factors for the risk of malaria infection. Children aged I-5 years and 5- 15 years were at greater risk of clinical episodes (OR 2.36, Cl I.4I-3.97, $\mathrm{P}=0.00 \mathrm{I}$ and $\mathrm{OR} 3.68, \mathrm{Cl} 2.42-5.6 \mathrm{I}, \mathrm{P}$ $<0.00$ I respectively).

Conclusion: These data show that local malaria transmission is restricted to the rainy season and strongly associated with proximity to the river. Transmission reducing interventions should, therefore, be timed before the rain-associated increase in mosquito numbers and target households located near the river. 


\section{Background}

The incidence and clinical presentation of Plasmodium falciparum malaria shows considerable variation between age groups [1], countries [2,3] and relatively short distances in single areas [4]. A key parameter defining the variation is the malaria transmission intensity. Transmission intensity is commonly quantified by the entomological inoculation rate (EIR), the estimated level of exposure to malaria infected mosquitoes. Spatial and temporal variation in transmission intensity is often not included in EIR estimates. This variation is particularly important in areas of low transmission intensity where few infected mosquitoes are caught and focal hotspots of malaria transmission may exist. Low transmission areas often have an unstable EIR $[1,4]$ with seasonal peaks that are commonly correlated with recent rainfall. Climatic [5-7], spatial [811], socio-economic [12-16] and other micro-environmental factors $[13,14]$ are important contributors to heterogeneity of malaria transmission in small geographic areas. Within a village there can be clustering of mosquitoes in a certain regions [17] with large proportions of vectors collected in relatively few of the houses $[18,19]$. Similar to clustering of mosquitoes, clinical malaria episodes can also be clustered in individuals [12] or housing groups $[12,16,20]$.

Factors that play a role in transmission can be studied using computerized mapping with global positioning systems (GPS) and geographical information systems (GIS) [10]. When environmental factors are coupled with clinical data, it may be possible to identify populations, households or areas that carry the heaviest burden of malaria or are the most important potential contributors to malaria transmission. Consequently, the impact of malaria control efforts can be maximized by implementing tailored control measures to carefully selected areas [20].

The study objective was to map malaria transmission patterns in a village in Lower Moshi, northern Tanzania, that is representative for this low transmission area. By determining micro-environmental factors that influence the risk of malaria, the aim was to identify high risk areas where transmission reducing interventions can be focused.

\section{Methods \\ Study site}

The study was conducted in the village of Msitu wa Tembo in lower Moshi (latitude $3^{\circ} 33^{\prime}$ S; longitude $37^{\circ} 17^{\prime} \mathrm{E}$ ) at an average altitude of $714 \mathrm{~m}$. Lower Moshi lies between the Masai Savannah and foothills of Mount Kilimanjaro and is hypoendemic for falciparum malaria. Irrigation from the nearby Karanga river makes the area suitable for small scale farming which is the predominant occupation.
The average annual rainfall is $615 \mathrm{~mm}$ (10 year average) and is highly seasonal with the period March-May accounting for $70 \%$ of the annual precipitation. The remainder falls during the unpredictable short rains in October-December. Between these two rainy seasons are a hot dry season during January-February and a cool dry season during June-September.

This study was part of a larger study on malaria immunity and received ethical approval from the ethical committees of the National Institute for Medical Research, the Kilimanjaro Christian Medical Centre, and the London School of Hygiene and Tropical Medicine.

\section{Demography}

All houses, roads and possible breeding sites were located with a hand-held GPS unit (Trimble GeoExplorer III). The program ArcView GIS 3.2 was then used to develop a map of the village and environs. Each house in the village was mapped, censused and its structure was evaluated. Rainfall data was collected from a nearby sugar plantation and measured daily at 21 points.

\section{Entomology \\ Mosquito light traps}

Mosquitoes were collected in 10 houses that were selected to be representative of the different housing structures in the village. Mosquitoes were caught with a standard Centre for Disease Control light traps (CDC, Atlanta, GA, USA) every week for one year (January-December 2004). Traps were hung at the end of an occupied bed with a bed net that was newly provided by the investigators. Traps were set for 12 hours, from $7 \mathrm{pm}$ to 7 am [22]. In the morning, traps were then collected and mosquito species determined and counted. Male Anopheles mosquitoes, Culicines and non-vector Anophelines were discarded.

\section{CSP ELISA}

Female Anopheles mosquitoes stored on silica gel for circumsporozoite protein (CSP) ELISA as described by Wirtz et al. [23]. Briefly, the head and thorax were removed for every mosquito and stored in an uncoated 96-well microtitre plate until the assays were performed. Samples were prepared individually and assayed in batches of four with positive batches re-assayed as single mosquitoes. Insectary reared unfed female Anopheles were used as negative controls with the kit supplied CSP antigen as positive control. Samples were read by eye and on an ELISA plate reader at $495 \mathrm{~nm}$. The EIR and confidence intervals were calculated as described by Drakeley et al. [24]. A conversion factor was used to adjust for the difference between light trap catches and man biting catches [25], giving the formula: infectious bites per person per year $=1.605^{*}$ (number of positive mosquitoes/number of traps) $* 365$. 


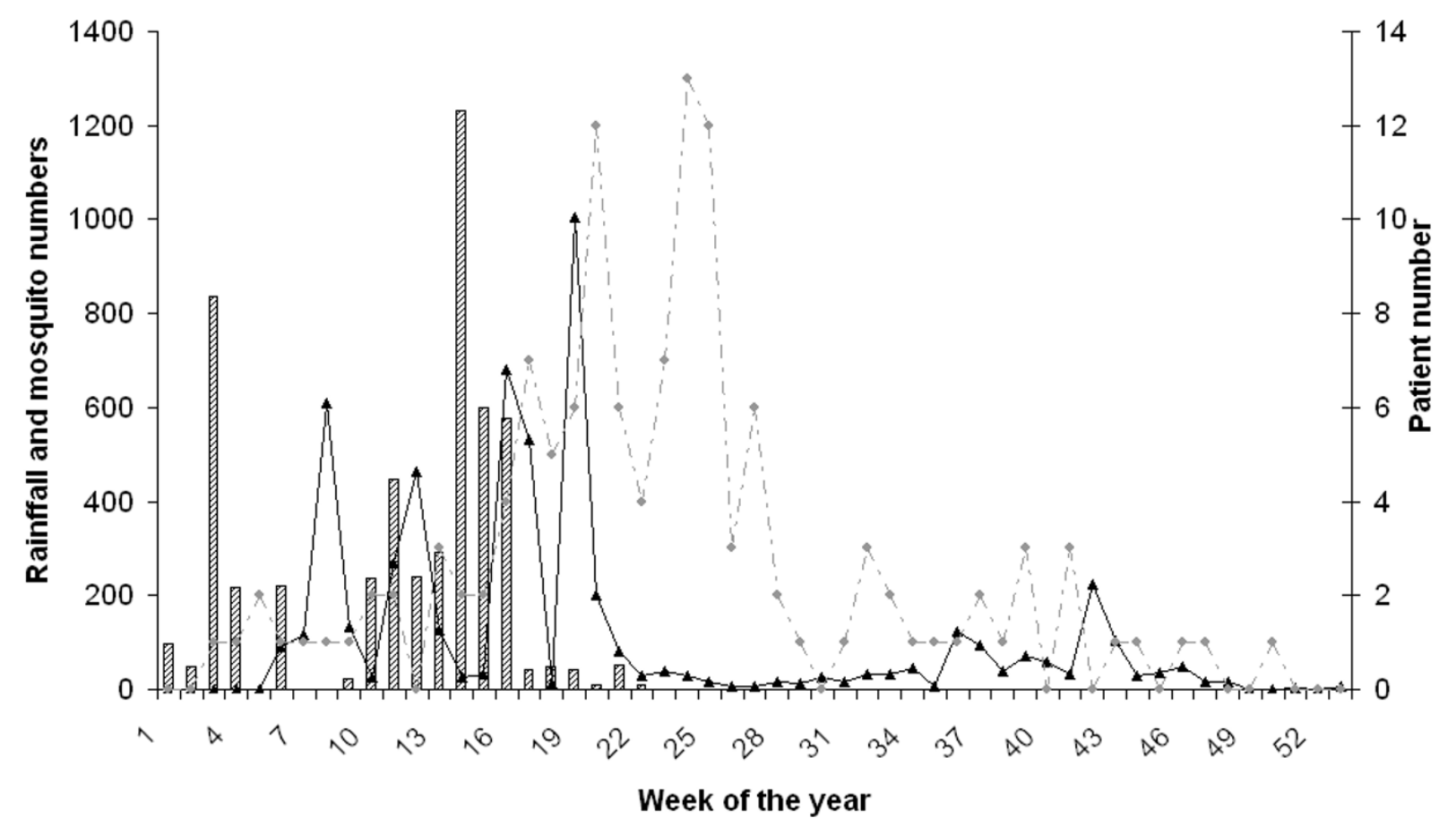

Figure I

Rainfall, numbers of mosquito and patients during 2004. Bars indicate the total rainfall per week collected in 21 rain gauges at the nearby sugar plantation (left hand y-axis). The solid line indicates the total proportion of female Anopheles mosquitoes caught per week (left hand y-axis). The broken line the total number of malaria cases seen by the health centre per week (right hand Y-axis).

\section{Mosquito speciation}

The protocol described by Scott et al. [26] was followed. Individual mosquitoes were randomly selected from ELISA test plates and the DNA extracted using the salt-TrisEDTA (STE) method. $50 \mu \mathrm{l}$ of mosquito triturate was added to $100 \mu \mathrm{l}$ of STE and mixed. Insectary reared Anopheles gambiae ss. were used as controls and PCR products were visualised using $1.5 \%$ agarose gels.

\section{Morbidity data}

A government clinic in the village centre, that was the nearest health facility for $\sim 8 \mathrm{~km}$, was used for collecting morbidity data. Each person visiting the clinic with suspected malaria was sent to the laboratory for confirmation by microscopy. Giemsa-stained slides were read by trained microscopists. Information about age, sex and residence were collected from the persons with a positive blood film and morbidity data were linked to individual houses. Individuals were considered patients if they had more than five $P$. falciparum parasites per 200 white blood cells in combination with symptoms suggestive of malaria. If the time between two malaria episodes of an individual exceeded one month, both were considered as separate episodes. Individuals were treated with sulphadoxine-pyrimethamine as first line treatment, with amodiaquine as second line and quinine reserved for severe cases as directed by the local clinical officer and in accordance with national guidelines.

\section{Data analysis}

Based on the rainfall and temperature data (not shown) the year was divided into three arbitrary seasons: dry (January-March), wet (April-June) and cool (July-December). The distance of individual households to the river was calculated in steps of 50 metres using ArcView GIS 3.2 software and subsequently categorised as close $(<1,200$ $\mathrm{m})$, intermediate $(1,200-1,600 \mathrm{~m})$ and $\operatorname{far}(>1,600 \mathrm{~m})$. Morbidity data and mosquito catches were summarized per week. Statistical analyses were performed in SPSS version 11.0.1 (SPSS Inc., Chicago, USA). Continuous variables were analysed using t-test, one-way ANOVA for normal distributed data or Wilcoxon rank sum test and Spearman's correlation coefficient for not normally distributed data. Categorical variables were analysed using 


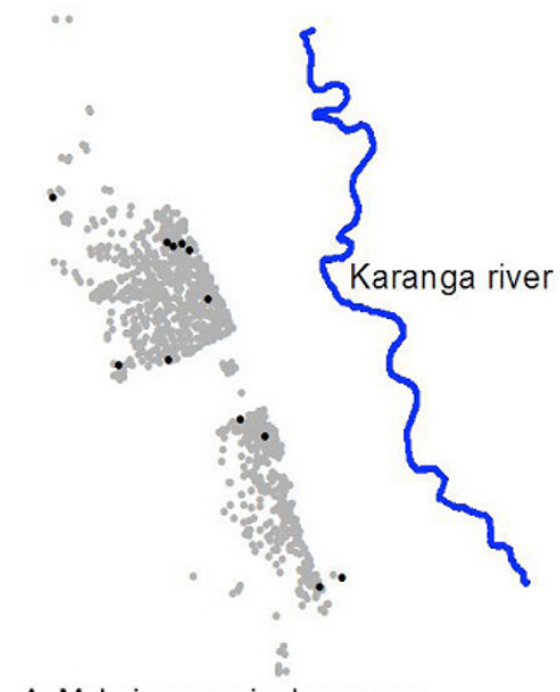

A. Malaria cases in dry season

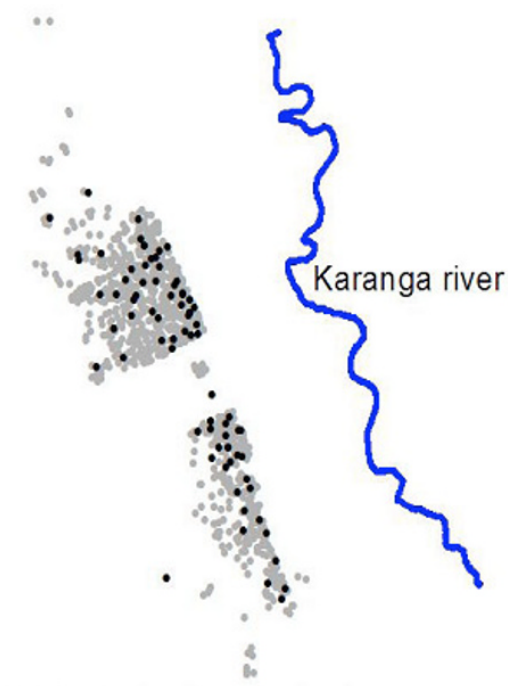

B. Malaria cases in wet season

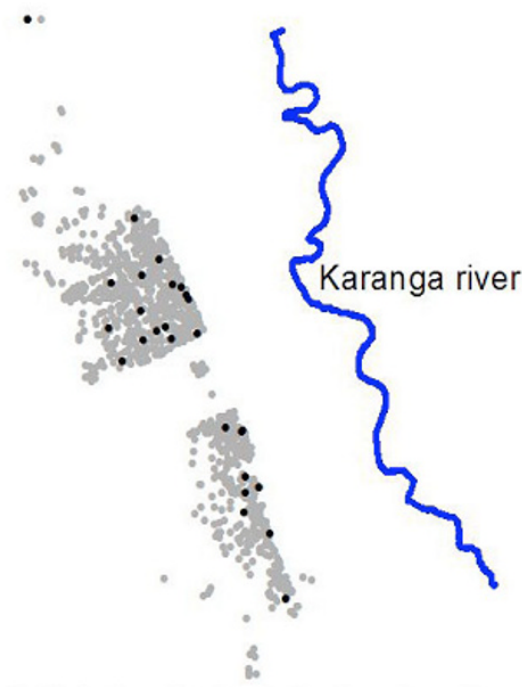

C. Malaria cases in cool season

Figure 2

Spatial distribution of malaria cases per season. Grey dots represent the houses. Black dots represent the malaria cases. Blue line indicates the river.

chi-square tests. Parasite densities were analysed after logtransformation (LN). Logistic regression models were used to determine the association between malaria incidence and housing conditions, age and distance to the river. Age was included in these models as a categorical variable ( $<5$ years, $5-14$ years and $\geq 15$ years old) and distance to the river as a continuous variable in steps of 50 meters.

\section{Results \\ Demography}

The village of Msitu consisted of 863 houses and a population of 3,388 individuals. Based on questionnaires used in an ancillary study (Shekelaghe et al in press), the vast majority of the population reside in the village permanently with travel outside largely restricted to the adult male population. The median age of the population was 17.0 years (IQR 7.0-30.0) and 51.1\% $(1,721 / 3,370)$ was male.

\section{Entomology}

A total of 510 CDC light traps were set in Msitu and 12859 mosquitoes were caught. Of the mosquitoes caught, $44.5 \%$ were of the Culex $(5,722 / 12,859)$ and $55,5 \%$ of the Anopheles genus $(7,137 / 12,859), 79 \%$ of the latter were female $(5,638 / 7,137)$. The seasonal relationship between rainfall, mosquito densities and malaria cases is shown in figure 1. There is a sequential progression of peaks in rainfall, number of female Anopheles mosquitoes caught and number of patients. No short rains (October -
December) were experienced in the year that the study was conducted.

In the CSP ELISA three female Anopheles mosquitoes were positive: one in March and two in May. Two of these positive mosquitoes were caught in one house. Based on CSP ELISA data and the number of traps set $(n=510)$, an overall EIR of 3.43 (95\% CI 0.7-9.9) infectious bites per person per year was calculated.

PCR amplification of mosquito samples was successful in $77.2 \%(61 / 79)$ of the randomly selected mosquitoes and indicated that all mosquitoes were of the An. arabiensis species $(61 / 61)$.

The number of houses selected was insufficient to determine a possible relation with distance to the river. However, despite the limited number of houses, medium or large window size (Wilcoxon Rank-sum, $\mathrm{p}=0.01$ ) and the absence of window screens (Wilcoxon Rank-sum, p < 0.001 ) were associated with a higher number of caught female Anopheles mosquitoes in univariate analysis.

\section{Malaria morbidity}

In the period January-December 2004, 130 malaria episodes were observed in 122 individuals. These individuals came from 105 households with three household experiencing more than two separate malaria episodes (three separate episodes in one man from a household of three individuals; four episodes in three individuals from a 
Table I: Risk factors associated with malaria incidence

\begin{tabular}{|c|c|c|c|c|}
\hline & \multicolumn{4}{|l|}{ Malaria incidence } \\
\hline & Crude OR & $\mathrm{P}$-value & Adjusted OR & $\mathrm{P}$-value \\
\hline Distance to breeding site & $0.95(0.91-0.98)$ & 0.003 & $0.96(0.92-0.998)$ & 0.04 \\
\hline \multicolumn{5}{|l|}{ Age } \\
\hline under 5 yrs & $2.44(1.46-4.06)$ & 0.001 & $2.36(|.4|-3.97)$ & 0.001 \\
\hline $5-14$ yrs & $3.80(2.5 \mathrm{I}-5.75)$ & $<0.001$ & $3.68(2.42-5.61)$ & $<0.001$ \\
\hline 15 yrs and older & 1.0 reference & & 1.0 reference & \\
\hline \multicolumn{5}{|l|}{ Window screen } \\
\hline Yes & $0.586(0.4 I-0.84)$ & 0.03 & $0.65(0.44-0.94)$ & 0.023 \\
\hline No & 1.0 reference & & 1.0 reference & \\
\hline \multicolumn{5}{|l|}{ Window size } \\
\hline Big/medium $\left(<50 \mathrm{~cm}^{2}\right)$ & $|.43|(0.944-2 .|7|)$ & 0.092 & $1.328(0.859-2.054)$ & 0.202 \\
\hline Small/no window $\left(>50 \mathrm{~cm}^{2}\right)$ & 1.0 reference & & 1.0 reference & \\
\hline
\end{tabular}

Crude and adjusted Odds Ratio (OR) are represented with a 95\% confidence interval between brackets.

household of six individuals; and four episodes in different individuals from a household of twelve individuals). In the dry season 17 patients reported at the health facility, compared to 85 in the wet season and 28 in the cool season $\left(\chi^{2}=62,3, p<0.001\right)$. In the dry season the geometric mean parasite density was 9309 (IQR 2,87943,002), in the wet season 4575 (IQR 1,040-28,119) and in the cool season 2864 (IQR 579-30,264) parasites/ $\mu$ l.

\section{Factors associated to malaria incidence}

The number of malaria cases was highest in houses close to the river that was considered as the main breeding site in the study area (Figure 2). The number of malaria cases was negatively associated to the distance to the river. Of those individuals who were living close to the river $(<1,200$ meters $) 5.1 \%(71 / 1,379)$ presented at the health centre with parasites during the study period compared to $3.0 \%(45 / 1,500)$ of those living at 1,200-1,600 meter and $2.8 \%(14 / 509)$ of those living at $>1600$ meter from the river $\left(\chi^{2}\right.$ test for trend $\left.=9.08, \mathrm{p}=0.0026\right)$. The proportion of cases living at $<1,200,1,200-1,600$ and $>1,600$ meter from the river was not different for the different seasons $\left(\chi^{2}=0,94, p=0.92\right)$. In addition to the distance to the river, three other factors appeared associated with malaria incidence (Table 1). There was a relation with age with malaria episodes most frequently occurring in children aged 5-14 years, followed by those below 5 years. The use of window screens resulted in a lower risk of malaria and malaria cases were more frequently observed in houses with larger windows, although the latter was not statistically significant. Other housing conditions such as roof type $(p=0.85)$, wall type $(p=0.90)$ and the presence of eaves $(p=0.32)$ were not related to risk of malaria.

\section{Discussion}

This study describes the pattern of malaria transmission in an area of very low transmission intensity, quantified by an estimated EIR of 3,43 (95\% CI 0.7-9.9) infectious bites per person per year. The findings indicate a seasonal pattern of malaria transmission with a clear geographical clustering of malaria cases associated with proximity to the river.

The strong relation between malaria incidence and the distance to a river (as a potential breeding site) has been observed before $[10,11]$; that this relation is apparent within a single village where a relatively small number of malaria episodes were observed is noteworthy. Msitu wa Tembo is a semi-arid area, which provides few breeding sites associated with irrigated areas on the banks of the river. In non-irrigated semi-arid areas transmission is often below detection level during the dry season, but high toward the end of the rainy season [27]. This study shows a similar pattern with a marked effect of the rainy season and high mosquito numbers concentrated in the 2-4 weeks after the heavy rainfall. This increase is presumably the results of an increase in mosquito breeding sites where mosquitoes mature in 10-14 days after oviposition. It was expected that the association between distance to the river and malaria episodes would be strongest in the dry season when the river is the only available breeding site and would become weaker after the rains when alternative breeding sites are more abundant. There was however no difference in the geographical distribution of malaria cases in the different seasons. This may in part be due to the low number of malaria cases in the dry season and that the GIS analysis was not adjusted for proximity 
of other houses. However, these data suggest that riverine breeding sites are the major source of vectors throughout the year. The principal effect of rainfall may be to increase the number and size of these sites maintaining the observed association of malaria cases and distance to the river. These data need interpreting in light of variations in rainfall patterns; in the year of study the annual rainfall was less the an $50 \%$ of the 10 year average $(280 \mathrm{~mm}$ vs $615 \mathrm{~mm}$ ) with no short rains.

The strong seasonal pattern of malaria transmission that we observed is typical of low transmission areas with seasonal rainfall $[1,4]$. In this study, malaria infections are observed in all age groups, as previously described [1] although malaria episodes are most common in children below fifteen years of age. This may reflect a lower level of immunity but may be partly attributable to a relative underestimation of adult malaria cases as well. Adults may be more likely to self medicate and, as a result, passive case detection may give incorrect estimates of age related disease patterns. Passive case detection may have resulted in an underestimation of symptomatic malaria episodes overall and definitely of parasite carriage, that can occur without symptoms even in low endemic areas [28]. However, whilst acknowledging that not all malaria infections will lead to a visit to the health clinic, there is no other health facility within a $10 \mathrm{~km}$ radius and clinic attendance was free during the study period, its is probable that all malaria related visits have been included and consider it unlikely that this has biased our results substantially.

There appeared to be clustering of malaria cases in certain houses. Although numbers were too small to allow firm conclusions, two out of three infected mosquitoes were caught in the same house and some households experienced several malaria episodes. This may indicate memorized site fidelity, as was previously noted in a nearby field site for An. arabiensis[29]

These findings provide a basis for transmission reducing interventions. Improving housing conditions such as window size and window screening can reduce the risk of malaria. In this respect, it is important to note that the major vector in this area, An. arabiensis [30] is known to show exophilic behaviour. This behaviour presents obstacles for interventions with treated bed-nets and indoor residual spraying and calls for greater focus on strategies such as larval control [31] or mass administration with gametocytocidal drugs to reduce the human infectious prior to the transmission season[32]. The data presented here suggest that with appropriate seasonal and spatial targeting these can be more effectively implemented.

\section{Conclusion}

The strong relation of malaria cases with the river suggest that focal malaria control is possible, either by larval control in river beddings or by selectively targeting households close to the breeding sites with transmission reducing interventions.

\section{Authors' contributions}

MJAMO conducted the fieldwork, analysis and wrote the manuscript, JTB was involved in data analysis and manuscript preparation. $\mathrm{OKM}, \mathrm{CH}, \mathrm{PL}, \mathrm{AM}$ and $\mathrm{HM}$ were involved in data-collection. FWM was involved in the study logistics and the planning of the study. CJD and JTB designed the study and were involved in data analysis and manuscript preparation.

\section{Acknowledgements}

We thank the community and the village elders of Msitu wa Tembo for their cooperation. J.T. Bousema was supported by NWO-WOTRO (2003/ 00702) and C.J. Drakeley by a research fellowship in tropical medicine (\#063516) from the Wellcome Trust. The study was conducted by PRIOR (NWO-WOTRO WIZ93-465) and the Joint Malaria Programme, a collaboration between the National Institute for Medical Research in Tanzania, Kilimanjaro Christian Medical Centre, London School of Hygiene and Tropical Medicine, and the University of Copenhagen.

\section{References}

I. Giha HA, Rosthoj S, Dodoo D, Hviid L, Satti GM, Scheike T, Arnot DE, Theander TG: The epidemiology of febrile malaria episodes in an area of unstable and seasonal transmission. Trans $R$ Soc Trop Med Hyg 2000, 94:645-65I.

2. Snow RW, Bastos dAI, Lowe BS, Kabiru EW, Nevill CG, Mwankusye S, Kassiga G, Marsh K, Teuscher T: Severe childhood malaria in two areas of markedly different falciparum transmission in east Africa. Acta Trop 1994, 57:289-300.

3. Snow RW, Marsh K: The consequences of reducing transmission of Plasmodium falciparum in Africa. Adv Parasitol 2002, 52:235-264.

4. Lusingu JP, Vestergaard LS, Mmbando BP, Drakeley CJ, Jones C, Akida J, Savaeli ZX, Kitua AY, Lemnge MM, Theander TG: Malaria morbidity and immunity among residents of villages with different Plasmodium falciparum transmission intensity in NorthEastern Tanzania. Malar J 2004, 3:26.

5. Maxwell CA, Chambo W, Mwaimu M, Magogo F, Carneiro IA, Curtis CF: Variation of malaria transmission and morbidity with altitude in Tanzania and with introduction of alphacypermethrin treated nets. Malar J 2003, 2:28.

6. Balls MJ, Bodker R, Thomas CJ, Kisinza W, Msangeni HA, Lindsay SW: Effect of topography on the risk of malaria infection in the Usambara Mountains, Tanzania. Trans R Soc Trop Med Hyg 2004, 98:400-408.

7. Drakeley CJ, Carneiro I, Reyburn H, Malima R, Lusingu JP, Cox J, Theander TG, Nkya WM, Lemnge MM, Riley EM: Altitude-dependent and - independent variations in Plasmodium falciparum prevalence in northeastern Tanzania. I Infect Dis 2005, |91:|589-1598.

8. Trape JF, Lefebvre-Zante E, Legros F, Druilhe P, Rogier C, Bouganali $H$, Salem G: Malaria morbidity among children exposed to low seasonal transmission in Dakar, Senegal and its implications for malaria control in tropical Africa. Am J Trop Med Hyg 1993 , 48:748-756.

9. Clarke SE, Bogh C, Brown RC, Walraven GE, Thomas CJ, Lindsay SW: Risk of malaria attacks in Gambian children is greater away from malaria vector breeding sites. Trans $R$ Soc Trop Med Hyg 2002, 96:499-506.

10. Staedke SG, Nottingham EW, Cox J, Kamya MR, Rosenthal PJ, Dorsey $\mathrm{G}$ : Short report: proximity to mosquito breeding sites as a 
risk factor for clinical malaria episodes in an urban cohort of Ugandan children. Am J Trop Med Hyg 2003, 69:244-246.

11. Van Der HW, Konradsen F, Amerasinghe PH, Perera D, Piyaratne MK, Amerasinghe FP: Towards a risk map of malaria for Sri Lanka: the importance of house location relative to vector breeding sites. Int J Epidemiol 2003, 32:280-285.

12. Gamage-Mendis AC, Carter R, Mendis C, De Zoysa AP, Herath PR, Mendis KN: Clustering of malaria infections within an endemic population: risk of malaria associated with the type of housing construction. Am J Trop Med Hyg 199I, 45:77-85.

13. Ghebreyesus TA, Haile M, Witten KH, Getachew A, Yohannes M, Lindsay SW, Byass P: Household risk factors for malaria among children in the Ethiopian highlands. Trans $R$ Soc Trop Med Hyg 2000, 94:17-2I.

14. Konradsen F, Amerasinghe P, Van Der HW, Amerasinghe F, Perera $D$, Piyaratne M: Strong association between house characteristics and malaria vectors in Sri Lanka. Am J Trop Med Hyg 2003, 68: $177-181$.

15. Lindsay SW, Jawara M, Paine K, Pinder M, Walraven GE, Emerson PM: Changes in house design reduce exposure to malaria mosquitoes. Trop Med Int Health 2003, 8:5 I2-5I7.

16. Brooker S, Clarke S, Njagi JK, Polack S, Mugo B, Estambale B, Muchiri $E$, Magnussen $P$, Cox J: Spatial clustering of malaria and associated risk factors during an epidemic in a highland area of western Kenya. Trop Med Int Health 2004, 9:757-766.

17. Ribeiro JM, Seulu F, Abose T, Kidane G, Teklehaimanot A: Temporal and spatial distribution of anopheline mosquitos in an Ethiopian village: implications for malaria control strategies. Bull World Health Organ 1996, 74:299-305.

18. Mbogo CN, Snow RW, Khamala CP, Kabiru EW, Ouma JH, Githure JI, Marsh K, Beier JC: Relationships between Plasmodium falciparum transmission by vector populations and the incidence of severe disease at nine sites on the Kenyan coast. Am J Trop Med Hyg 1995, 52:20I-206.

19. Keating J, Mbogo CM, Mwangangi J, Nzovu JG, Gu V, Regens JL, Yan G, Githure JI, Beier JC: Anopheles gambiae s.l. and Anopheles funestus mosquito distributions at 30 villages along the Kenyan coast. J Med Entomol 2005, 42:24I-246.

20. Carter R, Mendis KN, Roberts D: Spatial targeting of interventions against malaria. Bull World Health Organ 2000 78: $|401-14| 1$.

21. Trape JF, Lefebvre-Zante E, Legros F, Ndiaye G, Bouganali H, Druilhe $P$, Salem G: Vector density gradients and the epidemiology of urban malaria in Dakar, Senegal. Am J Trop Med Hyg 1992, 47: $181-189$

22. Mboera LE, Kihonda J, Braks MA, Knols BG: Influence of centers for disease control light trap position, relative to a humanbaited bed net, on catches of Anopheles gambiae and Culex quinquefasciatus in Tanzania. Am J Trop Med Hyg 1998, 59:595-596.

23. Wirtz RA, Burkot TR, Graves PM, Andre RG: Field evaluation of enzyme-linked immunosorbent assays for Plasmodium falciparum and Plasmodium vivax sporozoites in mosquitoes (Diptera: Culicidae) from Papua New Guinea. J Med Entomol 1987, 24:433-437.

24. Drakeley C, Schellenberg D, Kihonda J, Sousa CA, Arez AP, Lopes D, Lines J, Mshinda H, Lengeler C, Armstrong SJ, Tanner M, Alonso P. An estimation of the entomological inoculation rate for Ifakara: a semi-urban area in a region of intense malaria transmission in Tanzania. Trop Med Int Health 2003, 8:767-774.

25. Lines J, Curtis C, Wilkes T, Njunwa T: Monitoring human biting mosquitoes in Tanzania with light traps hung beside mosquito nets. Bull Ent Res 1991, 8 I:77-84.

26. Scott JA, Brogdon WG, Collins FH: Identification of single specimens of the Anopheles gambiae complex by the polymerase chain reaction. Am J Trop Med Hyg 1993, 49:520-529.

27. Dolo G, Briet OJ, Dao A, Traore SF, Bouare M, Sogoba N, Niare O, Bagayogo M, Sangare D, Teuscher T, Toure YT: Malaria transmission in relation to rice cultivation in the irrigated Sahel of Mali. Acta Trop 2004, 89: I47-I59.

28. Kleinschmidt I, Sharp B: Patterns in age-specific malaria incidence in a population exposed to low levels of malaria transmission intensity. Trop Med Int Health 200I, 6:986-99I.

29. McCall PJ, Mosha FW, Njunwa KJ, Sherlock K: Evidence for memorized site-fidelity in Anopheles arabiensis. Trans $R$ Soc Trop Med Hyg 200I, 95:587-590.
30. ljumba JN, Mosha FW, Lindsay SW: Malaria transmission risk variations derived from different agricultural practices in an irrigated area of northern Tanzania. Med Vet Entomol 2002, 16:28-38.

3I. Shililu J, Ghebremeskel T, Seulu F, Mengistu S, Fekadu H, Zerom M, Asmelash GE, Sintasath D, Mbogo C, Githure J, Brantly E, Beier JC, Novak RJ: Seasonal abundance, vector behavior, and malaria parasite transmission in Eritrea. J Am Mosq Control Assoc 2004, 20:155-164

32. von Seidlein L, Greenwood BM: Mass administrations of antimalarial drugs. Trends Parasitol 2003, 19:452-460.
Publish with Biomed Central and every scientist can read your work free of charge

"BioMed Central will be the most significant development for disseminating the results of biomedical research in our lifetime. "

Sir Paul Nurse, Cancer Research UK

Your research papers will be:

- available free of charge to the entire biomedical community

- peer reviewed and published immediately upon acceptance

- cited in PubMed and archived on PubMed Central

- yours - you keep the copyright
BioMedcentral 